\title{
Koordinasi Pemerintah dan Swasta dalam Program Corporate Social Responsibility (CSR) School Improvement di Kabupaten Pelalawan
}

Liza Trisnawati ${ }^{1}$, Amir Syamsuadi ${ }^{2}$, Seri Hartati ${ }^{3}$, Intan Reskiyanti ${ }^{4}$

Universitas Abdurrab, Jalan Riau Ujung No 73 Tampan, Riau

Corresponding Author: amir.syamsuadi@univrab.ac.id

Keyword:

Coordination;

Governmen;

Private;

Program

\begin{abstract}
This study aims to identify and explain the local government coordination of PT. Riau Andalan Pulp and Paper (RAPP) in implementing the school improvement program in Pelalawan Regency. The research method used is qualitative research by parsing the data descriptively. The theory used is the theory of Coordination in the management process according to Soewarno Handayaningrat which consists of Communication, Awareness of the Importance of Coordination, Competence of Participants, Commitment Agreements and Incentives, and Continuity of Planning. The results of this study indicate that the coordination built in the implementation of the school improvement program between the Regional Government, PT RAPP (private sector) and the Education Office in the field of education is good. This can be seen from the communication between the three actors in the collaboration that runs harmoniously and takes place in two directions. And the cooperation has been stated in a Memorandum of Understanding (MoU).
\end{abstract}

\begin{abstract}
Abstrak: Penelitian ini bertujuan untuk mengetahui dan menjelaskan koordinasi pemerintah daerah PT. Riau Andalan Pulp and Paper (RAPP) dalam mengimplementasikan program school improvement di Kabupaten Pelalawan. Metode penelitian yang digunakan yaitu penelitian kualitatif dengan mengurai data secara deskriptif. Teori yang digunakan adalah teori tentang Koordinasi dalam proses manajemen menurut Soewarno Handayaningrat yang terdiri dari Komunikasi, Kesadaran Pentingnya Koordinasi, Kompetensi Partisipan, Kesepakatan Komitmen dan Insentif, dan Kontinutas Perencanaan. Hasil penelitian ini menunjukkan bahwa koordinasi yang terbangun dalam pelaksanaan program school improvement antara Pemerintah Daerah, PT RAPP (swasta) dan Dinas Pendidikan dalam bidang pendidikan sudah baik. Hal ini dapat dilihat dari jalinan komunikasi antara ketiga aktor dalam kerjasama tersebut berjalan harmonis dan berlangsung secara dua arah. Dan kerjasama tersebut sudah dituangkan dalam Memorandum of Understanding (MoU).
\end{abstract}

Informasi Artikel: Disubmit: 20-10-2021, Revisi: 30-10-2021, Diterima: 06-11-2021

\section{PENDAHULUAN}

Pelaksanaan CSR merupakan bukti bahwa sektor swasta sebagai aktor negara nonpemerintah mempunyai andil dalam upaya perwujudan good governance yang bersinergi dan berkolaborasi (Rosyanti, Eldo, dan Novanto, 2019) dengan masyarakat dan pemerintah. Efektivitas tata kelola TI menjadi kebijakan dan pengelolaasn yang lebih baik (Hartati, Syamsuadi dan Arisandi, 2021). Tata pemerintahan adalah penggunaan wewenang ekonomi, politik dan administrasi guna mengelola urusan-urusan negara pada semua tingkat (Syamsuadi 2018). Pelaksanaan CSR merupakan kewajiban bagi setiap perusahaan yang ada di Indonesia sebagaimana telah diatur di dalam Peraturan Pemerintah (PP) No. 47 Tahun 2012 Tentang Tanggung Jawab Sosial dan Lingkungan yaitu tercantum dalam Pasal 74 Undang- 
Undang No. 40 Tahun 2007 tentang Perseroan Terbatas. Dalam pasal tersebut diatur bahwa: 1. Perseroan yang menjalankan kegiatan usahanya di bidang dan/atau berkaitan dengan sumber daya alam wajib melaksanakan Tanggung Jawab Sosial dan Lingkungan, 2. Tanggung Jawab Sosial dan Lingkungan sebagaimana dimaksud pada ayat (1) merupakan kewajiban Perseroan yang dianggarkan dan 53 diperhitungkan sebagai biaya Perseroan yang pelaksanaannya dilakukan dengan memperhatikan kepatutan dan kewajaran, 3. Perseroan yang tidak melaksanakan kewajiban sebagaimana dimaksud pada ayat (1) dikenai sanksi sesuai dengan ketentuan peraturan perundang-undangan, 4. Ketentuan lebih lanjut mengenai Tanggung Jawab Sosial dan Lingkungan diatur dengan Peraturan Pemerintah.

Salah satu perusahaan yang melaksanakan CSR di Kabupaten Pelalawan dan turut berperan aktif dalam membantu pembangunan daerah adalah PT Riau Andalan Pulp and Paper (RAPP) dengan meluncurkan program school improvement. Program school improvement merupakan kontribusi PT RAPP kepada Pemerintah Daerah Kabupaten Pelalawan dan menjadi salah satu program yang sejalan dengan program prioritas Kabupaten Pelalawan yaitu Pelalawan Cerdas. PT RAPP meluncurkan program School Improvement pada tahun 2018 di 5 Kabupaten dan melaksanakan program tersebut di 60 Sekolah Dasar. Dari 5 Kabupaten yang melaksanakan program School Improvement tersebut, penulis lebih tertarik untuk meneliti di Kabupaten Pelalawan karena di Kabupaten Pelalawan yang banyak menjadi sekolah mitra binaan PT RAPP, dengan banyaknya sekolah yang terbina dan terbantu maka hal ini bisa meningkatkan mutu sebuah pendidikan.

Tabel 1. Kabupaten/Kota se Provinsi Riau Pelaksana Program School Improvement dari PT RAPP Tahun 2018

\begin{tabular}{clc}
\hline No. & \multicolumn{1}{c}{ Kabupaten } & Jumlah sekolah \\
\hline 1 & Pelalawan & 18 Sekolah \\
2 & Kuantan Sengingi & 13 Sekolah \\
3 & Siak & 11 Sekolah \\
4 & Kepulauan Meranti & 10 Sekolah \\
5 & Kampar & 8 Sekolah \\
& Jumlah & 60 Sekolah \\
\hline
\end{tabular}

Sumber: Dokumen Perusahaan PT. RAPP, 2021

School Improvement atau Peningkatan mutu pendidikan dalam pandangan adalah suatu proses yang sistematis yang terus menerus meningkatkan kualitas proses belajar mengajar dan faktor-faktor yang berkaitan dengan itu, dengan tujuan agar menjadi target sekolah dapat dicapai dengan lebih efektif dan efisien. Dari pendekatan empirik yang dikaitkan dengan etimologi, koordinasi dikaitkan sebagai kegiatan yang dilakukan oleh berbagai pihak yang sederajat (equad in rank or order, of the same rank or order not subordinate) untuk saling memberi informasi dan mengatur bersama (menyepakati) hal tertentu. Secara normatif, koordinasi diartikan sebagai kewenangan untuk menggerakkan, menyerasikan, menyelaraskan, dan menyeimbangkan kegiatan-kegiatan yang spesifik atau berbeda-beda agar semuanya terarah pada tujuan tertentu. Sedangkan secara fungsional, koordinasi dilakukan guna untuk mengurangi akibat buruk spesialisasi dan mengefektifkan pembagian (Sitepu dan Maulana 2021)

Koordinasi sebagai penyelarasan kembali kegiatan-kegiatan yang saling bergantung atau penyusunan dari individu, kelompok atau organisasi yang dilakukan secara teratur guna mencapai tujuan bersama. Koordinasi sebagai bentuk ikhtiar dalam menyatukan kegiatankegiatan dari unit-unit kerja organisasi, sehingga organisasi dapat bergerak sebagai satu kesatuan yang bulat untuk melaksanakan seluruh tugas guna mencapai perihal yang sudah disusun dan direncanakan (Lesmana dan Wibowo 2021). Koordinasi yang dapat dilihat dari halhal berikut: a. Terdapat pembagian yang tugas dan pekerjaan yang jelas dalam organisasi. $b$. Terbentuknya suasana persaudaraan dan semangat kerja sama yang besar dalam organisasi. c. Adanya kontak-kontak dan komunikasi yang cukup di antara orang-orang dalam organisasi. d. Koordinasi ditetapkan dan dilaksanakan sebagai kesatuan perencana, pembimbingan dan pengendalian (Duryat 2021). 
Ada beberapa Penelitian sejenis dalam pelaksanaan Program CSR misalnya penelitian yang dilakukan oleh Khoirul Abror Ad-Dluha Ghoni, dkk, 2020 mengenai Implementasi Program Corporate Social Responsibility di Bidang Pendidikan (Studi pada Pemerintah Daerah Kabupaten Kutai Timur dan PT. Kaltim Prima Coal di Kecamatan Bengalon). Hasil penelitian menyebutkan bahwa implementasi program CSR dibidang pendidikan di Kecamatan Bengalon telah berhasil dilaksanakan oleh PT. KPC dilihat dari tiga aspek, yaitu accountability, transparency, dan sustainability (Ghoni, Wike, dan Novita 2020).

Penelitian berikutnya dilakukan oleh Deasy Arisanty, 2020 dengan judul implementasi Program CSR (Corporate Social Responsibility) PT. Adaro indonesia bidang pendidikan di Kecamatan Tanta Kabupaten Tabalong. Hasil penelitian menunjukkan bahwa program CSR yang dilaksanakan oleh PT. Adaro Indonesia terlaksana dengan baik dan efektif, namun ada ditemukan beberapa permasalahan dalam pelaksanaannya seperti ada sekolah yang pernah diberi bantuan, perihal laporan berita acara untuk arsip pihak sekolah ada yang tidak memiliki dan membuat pihak sekolah kesusahan menginput data atau barang yang termasuk hibah. Tetapi dari beberapa jenis program CSR dapat membuat sekolah lebih maju dan bisa membawa nama baik sekolahnya di tingkat nasional melalui program adiwiyata yang didapat dari pelatihan dan dikembangkan lebih lanjut sampai sekarang (Deasy 2020)

Sejalan dengan penelitian sejenis tersebut, penelitian ini secara komprehensif juga menganalisis kontribusi swasta (korporasi) terhadap pengembangan sektor pendidikan yakni dengan fokus kajian terhadap Koordinasi Pemerintah Dan Swasta Dalam Program Corporate Social Responsibility (CSR) School Improvement Di Kabupaten Pelalawan

\section{METODE PENELITIAN}

Penelitian ini dilakukan di Kabupaten Pelalawan Provinsi Riau yang dilakukan pada perangkat daerah BAPEDA Kabupaten Pelalawan selaku pihak pemerintah yang berhubungan dengan pihak swasta yakni PT. RAPP, pemerintah yang memiliki tanggung jawab dalam mengarahkan CSR untuk kebutuhan masyarakat. Penelitian ini menggunakan pendekatan penelitian kualitatif yakni penelitian yang memusatkan perhatian kepada konsep-konsep yang timbul dari data, perhatian bukan kepada angka-angka yang diperoleh melalui pengukuran empiris namun terhadap konsep-konsep yang ada didalamnya. Suatu peristiwa empiris dapat menghasilkan suatu konsep (Jaya 2020)

Jenis dan sumber data berupa data primer dan data sekunder. Data primer adalah diperoleh langsung dari informan penelitian dengan wawancara dengan tujuan untuk mengetahui secara langsung langkah koordinasi pemerintah dan swasta dalam program CSR ini. Sementara yang kedua adalah data sekunder data yang diperoleh penulis dari dokumentasi, media massa atau informasi dari sumber lain yang dapat mendukung objek dan investigasi penelitian. Data yang telah didapat kemudian dinarasikan kemudian dianalisis secara deskriptif. Pendekatan yang digunakan penulis dalam penelitian ini adalah pendekatan kualitatif, yaitu untuk mengetahui atau menggambarkan kenyataan dari kejadian yang diteliti sehingga memudahkan penulis untuk mendapatkan data yang objektif dalam rangka untuk mengetahui Koordinasi Pemerintah Daerah dan PT Riau Andalan Pulp and Paper (RAPP) dalam mengimplementasikan Program School Improvement Di Kabupaten Pelalawan.

\section{HASIL DAN DISKUSI}

Dalam menyikapi problematika dan masalah pendidikan yang ada di Kabupaten Pelalawan, Pemerintah Daerah juga turut melibatkan sektor swasta dengan membuat kebijakan tentang pelaksanaan Corporate Social Responsibility (CSR) yang diatur dalam Peraturan Daerah Kabupaten Pelalawan Nomor 1 Tahun 2018 tentang Tanggung Jawab Sosial dan Lingkungan Perusahaan, yang berisikan tentang Kewajiban Pemerintah Daerah, Kewajiban Perusahaan, Peran Masyarakat serta Sanksi dan Reward/Penghargaan terhadap Perusahaan yang telah melakukan kegiatan CSR di Wilayah Kabupaten Pelalawan. Dan diatur dalam Peraturan Daerah 
Provinsi Riau Nomor 6 Tahun 2012 Tentang Tanggung Jawab Perusahaan Provinsi Riau didalam Perda ini di jelaskan jenis-jenis program tanggung jawab sosial perusahaan yaitu Program Pemberdayaan Masyarakat, Program Kemitraan (Setiawan 2021), Program Bina Lingkungan, Donasi dan Promosi. Dengan meningkatnya mutu sebuah pendidikan bisa berimbas langsung pada peningkatan Sumber Daya Manusia.

Dalam melaksanaan program school improvement PT RAPP tidak bekerja sendiri (Wedayanti et al. 2021), tetapi bekerjasama dengan Pemerintah Daerah Kabupaten Pelalawan dan Dinas Pendidikan. Dari program tersebut PT RAPP dan Pemerintah Daerah Kabupaten Pelalawan melakukan MoU (Memorandum Of Understanding) yang dibuat bersama Dinas Pendidikan dan disepakati bersama (Utama 2020). Agar program tersebut dapat terlaksana dan berjalan sesuai dengan apa yang diharapkan, maka salah satu aspek yang diperhatikan adalah harus adanya koordinasi secara integratif diantara kedua pihak. Dengan adanya koordinasi, maka sinergi program (Susdarwono 2020) tersebut diantara PT RAPP dengan Pemerintah Daerah Kabupaten Pelalawan dapat tercapai. Koordinasi merupakan usaha untuk menjamin kelancaran mekanisme prosedur kerja dari berbagai komponen organisasi. Kelancaran mekanisme prosedur kerja harus dapat terjamin dalam rangka pencapaian tujuan organisasi dengan menghindari seminimal mungkin perselisihan yang timbul antara sesama komponen organisasi dan mengusahakan semaksimal mungkin kerjasama diantara komponen-komponen tersebut. School improvement adalah program CD PT RAPP yang berupaya untuk meningkatkan mutu pendidikan sekolah dasar. Program ini merupakan lanjutan dari program pelita pendidikan yang sebelumnya dilakukan oleh yayasan Tanoto Foundation yang didirikan oleh pak Sukanto Tanoto dan keluarga sebagai pemilik RAPP.

Adapun Program school improvement (Hidayatullah 2021) ini bertujuan untuk: 1. Meningkatkan kualitas pendidikan sekolah dasar tersebut melalui peningkatan kualitas pembelajaran siswa dengan kegiatan supervisi pembelajaran (serangkaia kegiatan membantu atau membimbing guru mengembangkan kemampuannya dalam mengelola proses pembelajaran untuk mencapai tujuan pembelajaran) pembelajaran aktif (Prenger, Poortman, dan Handelzalts 2021)(suatu pendekatan pembelajaran yang dapat mengembangkan potensi siswa melalui kegiatan mengamati, interaksi, komunikasi dan refleksi) dan pembiasaan membaca sebelum belajar (pembiasaan membaca yang rutin oleh siswa setiap 15 menit sebelum proses belajar mengajar dimulai) 2. Meningkatan akreditasi sekolah melalui kegiatan pelatihan akreditasi (bimbimgan teknis persiapan akreditasi sekolah mengenai pembentukan tim akreditasi sekolah, bedah instrumen akreditasi dan pengumpulan bukti fisit akreditasi) 3. Berkontribusi dalam mewujudkan sekolah adiwiyata (sekolah berbasis lingkungan, dimana warga sekolah bertanggung jawab dalam upaya perlingdungan dan pengelolaan lingkungan hidup, melalui proses pembelajaran dan tata kelola sekolah yang baik untuk mengdukung pembangunan berkelanjutan) melalui kegiatan PHBS (kegiatan memberdayakan guru siswa dan masyarakat lingkungan sekolah untuk mau melakukan pola-pola hidup sehat untuk menciptakan sekolah sehat) dan melibatkan peran serta masyarakat (PSM) (keterlibatan keluarga dan lingkungan dalam pembahasan masalah pendidikan, baik akademis maupun non akademis serta ikut dalam pada proses pengambilan keputusan dalam rencana pengembangan pendidikan di sekolah (Prenger, Poortman, dan Handelzalts 2021). Berdasarkan pendapat tentang indikator koordinasi, maka dalam penelitian menggunakan indikator koordinasi menurut Soewarno Handayaningrat (Triyono dan Yuniarsih 2020) sebagai fokus penelitian. Yakni: Komunikasi, Kesadaran Pentingnya Koordinasi, Partisipan, Kesepakatan, Komitmen, dan Insentif Koordinasi, Kontinuitas perencanaan. Kelima indikator tersebut digunakan untuk melihat seperti apa koordinasi yang berjalan selama ini antara Pemerintah Kompetensi Daerah dan PT RAPP, dalam melaksanakan program school improvement.

\section{Komunikasi}

Komunikasi adalah proses interaksi atau hubungan saling pengertian satu sama lain antara sesama manusia. Proses interaksi atau hubungan satu sama lain yang dikehendaki oleh seorang dengan maksimal agar dapat diterima dan dimengerti antara sesamanya. Esensi pada 
lembaga organisasi menjadikan komunikasi sangat penting karena komunikasi partisipan anggota akan semakin tinggi .

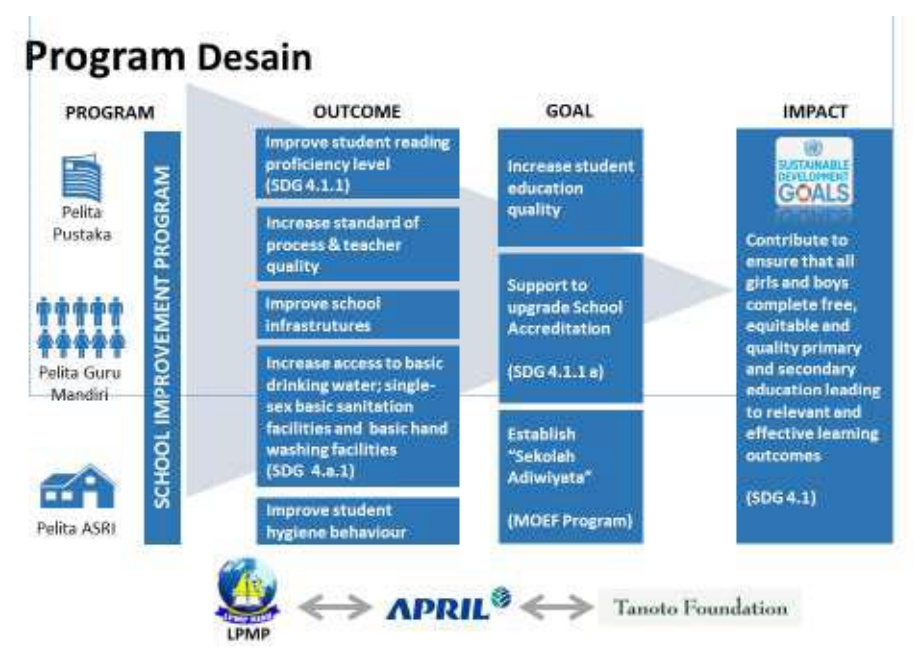

Gambar 1. Alur program School Improvement

Sumber: Dokumen Perusahaan PT. RAPP, 2021

Dalam hubungannya dengan aktivitas suatu organisasi selalu berkaitan dengan komunikasi internal dan eksternal (Ilfiana, Widodo, dan Setiarso 2021). Intensitas komunikasi tatap muka secara langsung saat mendiskusikan masalah moral akan jauh lebih baik daripada mengandalkan komunikasi tertulis. komunikasi secara umum membantu kelompok mendapatkan rasa "solidaritas" dan komunikasi tatap muka meningkatkan kemungkinan bahwa individu akan menepati janjinya untuk bekerja sama (Rusnaedy \& Haris, 2021). Berdasarkan informasi yang didapat bahwa dapat dipahami bahwa program pintar yang Tanoto Foundation lakukan merupakan bentuk kepedulian Tanoto kepada mitra pemerintah dalam mendukung program peningkatan kuatitas pendidikan dasar dan juga berupaya memperbaiki kualitas pembelajaran dan kepemimpinan sekolah. Dari program pintar (Reynolds dan Neeleman 2021) tersebut Community Development (CD) RAPP meluncurkan program school improvement atau peningkatan mutu sekolah dasar yang merupakan terusan dari program Tanoto Faoundation. Dari program school improvement tersebut menjadi salah satu bentuk kontribusi swasta kepada pemerintah untuk bisa meningkatkan kualitas sekolah dasar khususnya di Kabupaten Pelalawan di bidang pendidikan. Dimana pendidikan juga menjadi salah satu faktor penting dalam kemajuan dan bentuk kesejahteraan dari masyarakat. Dengan adanya komunikasi antara kedua aktor dalam kerjasama tersebut dapat berjalan harmonis dan berlangsung secara dua arah.

\section{Sadar Pentingnya Koordinasi}

Melihat persepsi dalam pelaksanaan koordinasi menjadi penting dalam upaya kesadaran akan pentingnya koordinasi. Kepemimpinan adalah kemampuan untuk memberikan pengaruh yang konstruktif kepada orang lain untuk melakukan usaha kooperatif mencapai tujuan yang sudah dicanangkan. Peran pemimpin di dalam koordinasi sangat penting guna membantu terwujudnya kesadaran tersebut. Dalam program school improvement juga melibatkan masyarakat untuk ikut dalam pembahasan masalah pendidikan, baik akademis maupun non akademis serta ikut dalam pada proses pengambilan keputusan dalam rencana pengembangan sekolah. Untuk mencapai program yang sudah direncanakan, RAPP melaksanakan program ini dengan menjalankan KKG, K3S dan pelatihan ToT untuk mengembangkan keahlian guru, kepala sekolah, pengawas sekolah dan komite sekolah yang bertujuan untuk meningkatkan kualitas pendidikan siswanya. Setelah melakukan pelatihan, para guru akan melaksanakan yang namanya refleksi, refleksi merupakan sebuah kegiatan yang dilakukan dalam proses belajar mengajar yang berupa penilaian oleh anak didik kepada guru, dimana refleksi ini sebagai tempat cerita anak didik untuk menyampaikan hal-hal yang dialami di dalam kelas sejak dimulai hingga berakhirnya pembelajaran. Refleksi yang dilaksanakan oleh 
guru disekolah juga akan dimonitor oleh school improvement untuk mengetahui apakah refleksi yang dilakukan oleh sekolah sudah berjalan dengan baik ataupun sebaliknya. Dan semua kegiatan yang dilaksanakan oleh RAPP dan sekolah akan dibantu dan dikoordinasi dengan tim yang ada di daerah yang sudah ditetapkan.

\section{Kompetensi Partisipan}

Didalam sebuah program membutuhkan koordinasi tidak dapat sukses tanpa adanya dukungan dari pihak lain yang memiliki kualitas dan kuantitas yang cukup.. Kualitias pihak yang berwenang berkaitan dengan keterampilan, profesionalitas, dan kompetensi dibidangnya, sedangkan kuantitas berkaitan dengan jumlah sumber daya manusia apakah sudah cukup untuk melingkupi seluruh kelompok sasaran. Bahwa dalam melaksanakan program school improvement pihak CD RAPP tidak bekerja sendiri tetapi juga turut melibatkan stakeholder terkait, seperti Pemerintah Daerah dan Dinas Pendidikan. Pihak CD RAPP akan menghadirkan kabidnya (kepala bidang), korwilnya (koordinasi wilayah) dan korwasnya (koordinasi pengawas) yang bergerak dibidang pendidikan yang sudah dikoordinasikan. Dengan menghadirkan orang-orang yang ada di kalangan pemerintah untuk mendukung suatu program agar program tersebut bisa berjalan dengan baik. Baik dari segi kualitas maupun kuantitas. Setelah menghadirkan stakeholder terkait, pihak CD RAPP dan Dinas Pendidikan akan mendatangkan dan mewawancarai guru, kepala sekolah, pengawas sekolah dan komite sekolah untuk diseleksi dan dijadikan fasilitator daerah sebagai perpanjangan tangan dari program school imrovement tersebut. Keterlibatan fasilitator daerah adalah sebagai penyalur ataupun menyampaikan program school improvement kepada guru dan sekolah-sekolah yang ada disekitar ataupun dibawah naungan dari pihak RAPP.

\section{Kesepakatan, Komitmen, dan Insentif}

Kesepakatan memberikan pengaruh yang dapat membuat orang yang menjadi targetnya mengikuti dan menyetujui apa yang ditawarkan di dalam kesepakatan tersebut. Bentuk kesepakatan yang ada dapat di lihat dari rincian peraturan-peraturan, prosedur-prosedur dan kebijakan-kebijakan. O'Reilly (1989: 11) menyebutkan komitmen karyawan pada organisasi sebagai ikatan kejiwaan individu terhadap organisasi yang mencakup keterlibatan kerja, kesetian, dan perasaan percaya terhadap nilai-nilai organisasi. Suatu bentuk komitmen yang muncul bukan hanya bersifat loyalitas yang pasif, tetapi juga melibatkan hubungan yang aktif dengan organisasi kerja yang memiliki tujuan memberikan segala usaha demi keberhasilan organisasi yang bersangkutan. Bentuk komitmen tersebut dapat dilihat dari sejauh mana individu-individu yang ada didalam organisasi tersebut bertanggungjawab melaksanakan tugas dan kewajiban atas dasar kesepakatan yang sudah disepakati bersama.

Dalam menjalankan program school improvement ada MoU yang dilakukan RAPP dengan Dinas Pendidikan dan Bupati (Pemerintah Daerah) yang mana pihak RAPP memiliki perencanaan untuk tiga tahun kedepan, program apa saja yang dapat meningkatkan program school improvement di Kabupaten Pelalawan. Dengan adanya MoU diantara kedua belah pihak yang bertujuan memudahkan proses suatu kesepakatan dengan waktu yang sudah ditentukan. Dimana sekolah yang ada di Kabupaten Pelalawan tidak lepas dari pemerintah, maka harus adanya koordinasi antara RAPP dengan Pemerintah Daerah dan Dinas Pendidikan. Sedangkan ada fasilitator daerah yang menyatakan bahwa tidak adanya MoU yang dilakukan pihak RAPP dengan sekolah yang menjadi mitra binaan, karena sekolah berada di area operasionalnya RAPP. Sedangkan ada fasilitator daerah dari sekolah lain yang mnegnyatakan bahwa sekolah akan dilepas ketika sekolah sudah mampu mandiri. Tetapi beberapa pihak dari sekolah masih kurang mengetahui apakah sekolah-sekolah yang dibina nantinya akan tetap menjadi sekolah binaan atau akan dilepas ketika sekolah sudah mampu untuk menjalan program yang sudah diberikan oleh pihak RAPP. Dan bentuk kesepakatan, komitmen dan insentif yang dilakukan antara pihak RAPP dengan sekolah masih kurang baik karena masih ada ketidaksinkronan antara keduanya.

\section{Kontiunitas Perencanaan}

Keberlajutan suatu kegiatan memang sangat dibutuhkan, keberlajutan akan sesuatu hal dapat memberikan timbal balik terhadap apa yang telah dilaksanakan untuk perubahan lebih baik ke depannya. perencanaan dapat didefinisikan sebagai keseluruhan proses pemikiran dan 
penentuan secara matang daripada hal-hal yang akan dikerjakan dimasa yang akan datang dalam rangka pencapaian tujuan yang telah ditentukan. umpan balik adalah pengetahuan yang diperoleh terkenaan dengan sesuatu tugas, perbuatan atau respons yang telah diberikan. Umpan balik didapat setelah melakukan evaluasi terhadap pelaksanaan yang sudah dilakukan evaluasi dapat juga diartikan sebagai "proses menilai sesuatu berdasarkan kriteria atau tujuan yang telah ditetapkan yang selanjutnya diikuti dengan pengambilan keputusan atas obyek yang dievaluasi. Bahwa perencanaan yang dilakukan oleh RAPP sudah mengalami perubahan yang cukup signifikan, seperti yang disampaikan oleh narasumber bahwa sebelum adanya program school improvement sekolah mereka tidak layak untuk mengikuti adiwiyata, dan pengelolaan sampah yang masih banyak. Setelah mengikuti program school improvement beberapa sekolah mengalami perubahan yang signifikan seperti ikut program kaizen (kaizen adalah suatu metode praktis yang berfokus pada tindak perbaikan manuju ke arah yang labih baik dari sebelumnya dalam menjalankan proses operasional), green house, pondok baca, literasi berjalan, yang sebelumnya program tersebut tidak berjalan disekolah.

Untuk melihat perubahan dari program school improvement maka diadakan Baseline (Baseline adalah informasi dasar yang dihimpun sebelum suatu program dimulai). Baseline juga digunakan sebagai pembanding sebelum adanya program dan setelah adanya program. Perbandingan dimulai dari modul 1 apa yang sekolah terapkan mengenai Manajemen Berbasis Sekolah (MBS) dan Proses Belajar mengajar. Setelah melakukan modul 1 akan dinilai oleh RPO (staf Community Development RAPP) apakah sudah ada perubahan, setelah modul 1 diterapkan, guru akan diberikan lagi pelatihan untuk modul 2 yang terdiri dari Manajemen Berbasis Sekolah (MBS) Peran Serta Masyarakat (PSM) dan Proses Belajar Mengajar (PBM) yang nantinya akan dipresntasikan hasil dari kinerja kepala sekolah, guru, cara mengajar, nilai prestasi anak, lingkungan sekolah dan nilai akreditasi sekolah. Selain sekolah, Dinas Pendidikan merasa terbantu oleh program school improvement, karena program yang diluncurkan oleh RAPP sejalan dengan program unggulan Bupati Pelalawan yaitu Pelalawan Cerdas. Untuk melihat perubahan setelah adanya program school improvement ada gambar yang menunjukkan indikator perubahan dalam peningkatan kualitas pembelajaran di sekolah dan peningkatan Kepemimpinan, tat kelola dan manajemen pendidikan. Sebelum masuk dalam pembahasan penulis juga sudah menyampaikan data berupa baseline dan midline di latar belakang.

Adapun faktor-faktor yang mendukung pelaksanaan program school improvement adalah: 1. Pemerintah, sebagai salah satu stakeholder dalam pelaksanaan program memiliki kepentingan yang besar terhadap program perusahaan. Dengan kekuasaan, legitimasi pemerintah cenderung untuk mempengaruhi program agar sejalan dengan orientasi program. Pemerintah juga lebih banyak mendukung pelaksanaan program perusahaan menyediakan regulas maupun fasilitas. Pemerintah juga turut mensosialisasikan program dan menjembati komunikasi perusahaan dengan masyarakat. 2. Swasta, disini adalah Perusahaan. Perusahaan harus mampu memberikan manfaat bagi stakeholder-nya. Manfaat tersebut dapat diberikan dengan cara menerapkan program. Dengan adanya program tersebut pada perusahaan diharapkan akan meningkatkan kesejahteraan bagi masyarakat lokal. Sehingga diharapkan terjalin hubungan yang baik antara perusahaan dengan lingkungan sekitar.3. Masyarakat, mempunyai hak untuk menyampaikan aspirasinya yang diatur dalam Peraturan Daerah Provinsi Riau Nomor 6 tahun 2012 tentang Tanggung Jawab Sosial Perusahaan di Provinsi Riau tertuang pada pasal 8 bagian d yang berbunyi perusahaan berkewajiban menerima usulan masyarakat baik perorangan maupun kelompok yang sesuai dengan kebutuhan masyarakat.

\section{KESIMPULAN}

Bahwa dari uraian diatas dapat ditarik sebuah kesimpulan bahwa koordinasi yang dilakukan oleh PT RAPP, Pemerintah Daerah dan Dinas Pendidikan sudah berjalan dengan baik . Dengan adanya koordinasi, maka sinergi program tersebut antara PT RAPP dengan Pemerintah Daerah Kabupaten Pelalawan dapat tercapai, dengan menginformasikan program school improvement ini kepada Pemerintah Daerah dan Dinas Pendidikan sebagai bentuk kontribusi 
RAPP terhadap Pemerintah Daerah. Dalam menjalankan program school improvement ini selain CD RAPP, Pemerintah Daerah dan Dinas Pendidikan serta Fasilitator Daerah, kepala sekolah, dan pengawas sekolah terjalin kerjasama yang baik dan mempermudah pencapaian hasil yang memuaskan. Pihak-pihak yang berwenang yang terlibat dan mengawasi jalannya koordinasi. Seperti Pemerintah Daerah, Dinas Pendidikan pada tim area operasional, kabid, korwil dan korwas juga ikut terlibat aktif dalam pelaksanaan program school improvement. Selain itu fasilitator daerah juga terlibat aktif dalam program school improvement sebagai perpanjangan tangan dari CD RAPP dan untuk mengawasi jalannya koordinasi pelaksanaan program.

Adapun Bentuk kesepakatan, komitmen dan insentif yang dilakukan CD RAPP dengan Pemerintah Daerah dan Dinas Pendidikan adalah dengan melakukan MoU sebagai bentuk kerjasama dan keseriusan PT RAPP terhadap pelaksanaan dan jalannya program school improvement agar dapat berkontribusi secara berlanjut kepada Pemerintah Daerah dan tentunya dapat membantu sekolah-sekolah yang ada di Kabupaten Pelalawan.

\section{UCAPAN TERIMAKASIH}

Peneliti mengucapkan terimakasih kepada LPPM Universitas Abdurrab yang sudah memfasiltasi dan mendukung penulis untuk melakukan penelitian ini. Dan juga kepada seluruh pihak-pihak terkait baik stakeholder Pemerintah Daerah Kabupaten Pelalawan dan juga dari pihak perusahaan PT. RAPP yang telah banyak memberikan data dan informasi mengenai penelitian ini.

\section{REFERENSI}

Deasy, Arisanty. 2020. "Implementasi Program CSR (Corporate Social Responsibility) Pt. Adaro Indonesia Bidang Pendidikan di Kecamatan Tanta Kabupaten Tabalong." JPG Uurnal Pendidikan Geografi) 3(6): 1-13.

Duryat, H Masduki. 2021. Kepemimpinan Pendidikan: Meneguhkan Legitimasi Dalam Berkontestasi Di Bidang Pendidikan. Penerbit Alfabeta.

Ghoni, Khoirul Abror Ad-Dluha, Wike Wike, dan Asti Amelia Novita. 2020. "Implementasi Program Corporate Social Responsibility di Bidang Pendidikan (Studi pada Pemerintah Daerah Kabupaten Kutai Timur dan PT. Kaltim Prima Coal di Kecamatan Bengalon)." Jurnal Ilmiah Administrasi Publik 6(1): 71-81.

Hartati, Seri, Amir Syamsuadi, dan Diki Arisandi. 2021. "University Level Management Toward Industrial Revolution 4.0 using COBIT 5 Framework." Journal of Physics: Conference Series 1783(1): 12021.

Hidayatullah, Muhammad Fahmi. 2021. "Quality Improvement Design at Islamic Schools PostCovid-19 Pandemic in Elementary School and Integrated Early Childhood Education of Saleh Children, Malang City." Jurnal Tatsqif 19(1): 81-97.

Ilfiana, Ayu, Wahono Widodo, dan Pirim Setiarso. 2021. "The Improvement of Student's Critical Thinking Skills Through the Development of Science Learning Material Based Socioscientific Issues with Interactive Multimedia-Assisted on Gadget." Jurnal Penelitian Pendidikan IPA 7(4): 496-501.

Jaya, I Made Laut Mertha. 2020. Metode Penelitian Kuantitatif dan Kualitatif: Teori, Penerapan, dan Riset Nyata. Anak Hebat Indonesia.

Lesmana, Dadang, dan Bagus Rai Wibowo. 2021. “Analisis Pemanfaatan Dana Corporate Social Responsibility (CSR) dalam Pembangunan di Kabupaten Kutai Timur (Studi Kasus Kecamatan Teluk Pandan Dan Bengalon)." JURNAL RISET PEMBANGUNAN 3(2): 78-87.

Prenger, Rilana, Cindy L Poortman, dan Adam Handelzalts. 2021. "Professional learning networks: From teacher learning to school improvement?" Journal of educational change 22(1): 13-52.

Reynolds, David, dan Annemarie Neeleman. 2021. "School Improvement Capacity-A Review and a Reconceptualization from the Perspectives of Educational Effectiveness and Educational Policy." Concept and Design Developments in School Improvement Research: 27-40.

Rosyanti, Erny, Dwian Hartomi Akta Padma Eldo, dan Riza Awal Novanto. 2019. "Collaborative 
Governance Sebagai Upaya Dalam Akselerasi Pembangunan Desa." Journal of Governance and Local Politics (JGLP) 1(2): 137-56.

Rusnaedy, Z., \& Haris, A. (2021). Advocacy Coalition in The Arrangement of The Coastal Slum Area of Untia in Makassar. Journal of Governance and Public Policy, 8(1), 71-81.

Setiawan, Hendy. 2021. "Inovasi Pelayanan Publik Lukadesi (Keluarga Berduka Desa Siaga) di Sleman DI Yogyakarta." Journal of Governance and Local Politics (JGLP) 3(1): 1-22.

Sitepu, Putri Andayani Br, dan Rio Yusri Maulana. 2021. "Tata Kelola Program Corporate Social Responsibility (Csr) Melalui Konsep Collaborative Governance dalam Menunjang Program Pembangunan Daerah." Jurnal Ilmu Pemerintahan Widya Praja: 80-90.

Susdarwono, Endro Tri. 2020. "Kebijakan Sinergitas R \& D Pemerintah, Komunitas Epistemik, dan Sektor Swasta dalam Percepatan Kemandirian Industri Pertahanan." Journal of Governance and Local Politics (JGLP) 2(2): 106-30.

Syamsuadi, Amir. 2018. "Membangun Demokrasi Pemerintahan di Riau Dalam Perspektif Budaya Melayu." Jurnal Dinamika Pemerintahan 1(1): 1-10.

Triyono, Joko, dan Rulida Yuniarsih. 2020. "Koordinasi Pembangunan Fisik Di Desa Permata Kecamatan Terentang Kabupaten Kubu Raya." GOVERNANCE-Jurnal Ilmu Pemerintahan $9(2)$.

Utama, Andrew Shandy. 2020. "Pemanfaatan program CSR perusahaan untuk pemberdayaan perekonomian masyarakat Kabupaten Pelalawan di masa pandemi Covid-19." In Unri Conference Series: Community Engagement, , 77-83.

Wedayanti, Made Devi, Achmad Nurmandi, Hasse Jubba, dan Septa Juliana. 2021. "Implementation of Corporate Social Responsibility in PT. Riau Andalan Pulp and Paper in Pelalawan District, Riau Province." In INCEESS 2020: Proceedings of the 1st International Conference on Economics Engineering and Social Science, InCEESS 2020, 17-18 July, Bekasi, Indonesia, European Alliance for Innovation, 71. 